\title{
Dexamethasone Intravitreal Implant for Early Treatment and Retreatment of Macular Edema Related to Branch Retinal Vein Occlusion: The Multicenter COBALT Study
}

\author{
Young Hee Yoon ${ }^{\mathrm{a}}$ Jong Woo Kim ${ }^{\mathrm{b}}$ Joo Yong Lee ${ }^{\mathrm{a}}$ In Taek Kim ${ }^{\mathrm{c}}$ \\ Se Woong Kang ${ }^{d}$ Hyeong Gon Yu ${ }^{e}$ Hyoung Jun Koh ${ }^{f}$ Sung Soo Kim ${ }^{f}$ \\ Dong-Jin Chang ${ }^{g}$ Susan Simonyi ${ }^{\text {h }}$
}

\begin{abstract}
a Department of Ophthalmology, Asan Medical Center, University of Ulsan College of Medicine, Seoul, Republic of Korea; 'bepartment of Ophthalmology, Kim's Eye Hospital, Konyang University College of Medicine, Seoul, Republic of Korea; 'Department of Ophthalmology, Kyungpook National University School of Medicine, Daegu, Republic of Korea; ${ }^{\mathrm{d}}$ Department of Ophthalmology, Samsung Medical Center, Sungkyunkwan University School of Medicine, Seoul, Republic of Korea; ' Department of Ophthalmology, Seoul National University College of Medicine, Seoul, Republic of Korea; ${ }^{\mathrm{f}}$ Department of Ophthalmology, Yonsei University College of Medicine, Seoul, Republic of Korea; ${ }^{9}$ Allergan, Seoul, Republic of Korea; ${ }^{\text {h}}$ Medical Affairs, Allergan Pte. Ltd., Singapore, Singapore
\end{abstract}

\section{Keywords}

Macular edema $\cdot$ Retinal vein occlusion - Dexamethasone implant · Early treatment

\begin{abstract}
Purpose: To evaluate the effect of dexamethasone intravitreal implant for macular edema (ME) following branch retinal vein occlusion (BRVO) in Korean patients. Methods: We performed a prospective, open-label, multicenter study of 71 patients with ME for $<3$ months. Retreatment was allowed $\geq 4$ months from the last injection. Results: At 6 and 12 months, mean \pm SD best-corrected visual acuity (BCVA) improvement was $18.6 \pm 12.9$ and $15.3 \pm 15.0$ letters, respectively. Approximately $70 \%$ of maximum treatment response was observed after 1 week. Over the 12-month period, 32
\end{abstract}

and $49 \%$ of patients received 1 and 3 injections, respectively, with a mean \pm SD interval of $20.0 \pm 5.0$ weeks. Patients who required 3 injections had higher central retinal thickness (CRT) and larger macular nonperfusion at baseline compared to those requiring only 1 injection. Adverse events included increased intraocular pressure (35\%) and newly diagnosed cataract (16\%). Conclusions: Intravitreal dexamethasone treatment with an interval of $\geq 4$ months provides rapid and significantly better improvement in BCVA and CRT in patients with BRVO-associated ME.

(c) 2018 The Author(s)

Published by S. Karger AG, Basel

This study was conducted at seven sites in Korea (ClinicalTrials.gov identifier: NCT01903720).

\begin{tabular}{ll}
\hline KARGER & $\begin{array}{l}\text { Ko 2018 The Author(s) } \\
\text { Published by S. Karger AG, Basel }\end{array}$ \\
Open ciccess \\
E-Mail karger@karger.com & This article is licensed under the Creative Commons Attribution- \\
wwww.karger.com/oph & $\begin{array}{l}\text { NonCommercial-NoDerivatives 4.0 International License (CC BY- } \\
\text { NC-ND) (http://www.karger.com/Services/OpenAccessLicense). } \\
\text { Usage and distribution for commercial purposes as well as any dis- } \\
\text { tribution of modified material requires written permission. }\end{array}$
\end{tabular}

Young Hee Yoon, MD, PhD

Department of Ophthalmology, Asan Medical Center

University of Ulsan College of Medicine

88 Olympic-ro 43-gil, Songpa-gu, Seoul 05505 (Republic of Korea)

E-Mail yhyoon@amc.seoul.kr 


\section{Introduction}

Retinal vein occlusion is the second most common cause of vision loss due to retinal vascular disorder [1]. The incidence and prevalence of branch retinal vein occlusion (BRVO), involving a single retinal vein, is more common than central retinal vein occlusion (CRVO) [14]. Retinal vein occlusion is associated with macular edema (ME) and may result in vision loss [1].

Several therapeutic options, including laser photocoagulation [5], anti-vascular endothelial growth factor (anti-VEGF) therapies [6], and intravitreal injections of triamcinolone $[7,8]$ and dexamethasone [9], are available for treating BRVO-associated ME. Evidence for the use of these therapies is accumulating; however, the optimal treatment choice remains unclear.

Dexamethasone implant $\left(\right.$ Ozurdex $^{\circledR} 0.7 \mathrm{mg}$ dexamethasone intravitreal implant; Allergan, Inc., Irvine, CA, USA) is approved in Korea for retinal vein occlusion, noninfectious posterior uveitis, and diabetic ME. The implant is a novel intravitreal drug delivery system consisting of a biodegradable copolymer of lactic acid and glycolic acid, which contains micronized dexamethasone. A total dose of $0.7 \mathrm{mg}$ dexamethasone is delivered gradually to the vitreous, allowing for sustained drug levels to the target areas while reducing the potential for side effects typically observed from steroid administration through other delivery routes.

Dexamethasone intravitreal implant decreases central retinal thickness (CRT), which is significantly associated with improvement in best-corrected visual acuity (BCVA) at 6 months after treatment [10]. In the phase 3 GENEVA study, dexamethasone intravitreal implant significantly improved BCVA [11] and had a favorable safety profile over 12 months [12] in patients with ME associated with BRVO or CRVO. However, only $16.4 \%$ of patients had a disease duration $<90$ days [11]. Early treatment is associated with better visual outcomes $[13,14]$, and visual outcome can be improved for BRVO-associated ME when treatment is initiated within 2 weeks after onset of ME [14]. Conversely, delayed treatment of ME compromises prognosis, with each 1-month increase in ME duration being significantly associated with a lower likelihood of achieving a BCVA improvement of $\geq 15$ letters or a CRT reduction of $\geq 200 \mu \mathrm{m} 6$ months after treatment [13].

Because the GENEVA study had some gaps that needed to be addressed under "real-world" conditions, particularly early treatment and treatment intervals $<6$ months, we sought to evaluate the efficacy and safety of dexamethasone intravitreal implant $(0.7 \mathrm{mg})$ in early treatment and retreatment of BRVO-associated ME of $<3$ months' duration. The earliest response to treatment and the optimal retreatment interval of dexamethasone intravitreal implant were also evaluated.

\section{Methods}

\section{Study Design}

This prospective, noncomparative, open-label clinical trial the COBALT study - was conducted at seven sites in Korea (Asan Medical Center, Gangnam Severance Hospital, Kim's Eye Hospital, Kyungpook National University Hospital, Samsung Medical Center, Seoul National University Hospital, and Severance Hospital) between January 13, 2014 and May 30, 2015 (ClinicalTrials.gov identifier: NCT01903720).

\section{Study Population}

Adults ( $\geq 18$ years old) with treatment-naïve BRVO-associated ME involving the center of the fovea for $<3$ months with visual acuity loss attributable to ME (BCVA between 19 and 73 letters, approximately $20 / 400$ to $20 / 40$ Snellen equivalent), and CRT $\geq 340 \mu \mathrm{m}$ as determined by spectral-domain optical coherence tomography (Spectralis, Heidelberg, Germany; Cirrus, Carl Zeiss Meditec, Dublin, CA, USA) were enrolled. Women of childbearing potential were eligible to participate if they were using a highly effective contraceptive and were not pregnant, planning a pregnancy, or lactating. If in any patient both eyes were eligible for the study, the eligible eye with the shorter disease duration was used as the study eye.

Patients with uncontrolled, systemic disease or any condition that, in the opinion of the investigator, might interfere with or preclude participation in the study were excluded. Patients participating in a clinical study within 30 days of baseline, using systemic steroids within 1 month, using immunosuppressants, immunomodulators, antimetabolites, and/or alkylating agents within 3 months, or warfarin or heparin within 2 weeks were not eligible. Further, patients with known allergy, hypersensitivity, or contraindication to the study drug, its components, fluorescein, or povidone iodine were excluded.

The main ocular exclusion criteria were evidence of vitreoretinal interface disease or ocular condition that might contribute to or affect ME, any ocular condition other than ME that affects visual acuity (e.g., cataract), vitrectomized eye, aphakia, marked intraocular pressure (IOP) elevation in response to steroid treatment, history of glaucoma or ocular hypertension, or any of the following $\leq 3$ months before study entry: intraocular surgery or injection, laser treatment, or peribulbar steroid injection.

\section{Study Procedure}

Patients were screened (visit 0 ) within 2 weeks prior to the baseline visit (day 0 ). Eligible patients received their initial dexamethasone $(0.7 \mathrm{mg})$ implant via intravitreal injection on day 0 and were followed for 12 months. Perfusion of the optic nerve head was checked immediately after injection, and patients were monitored for elevation of IOP (within $30 \mathrm{~min}$ of injection) and for endophthalmitis. Patients were instructed to report any signs of endophthalmitis without delay. Biomicroscopy or telephone follow-up was conducted for each patient between 2 and 7 days after injection. 


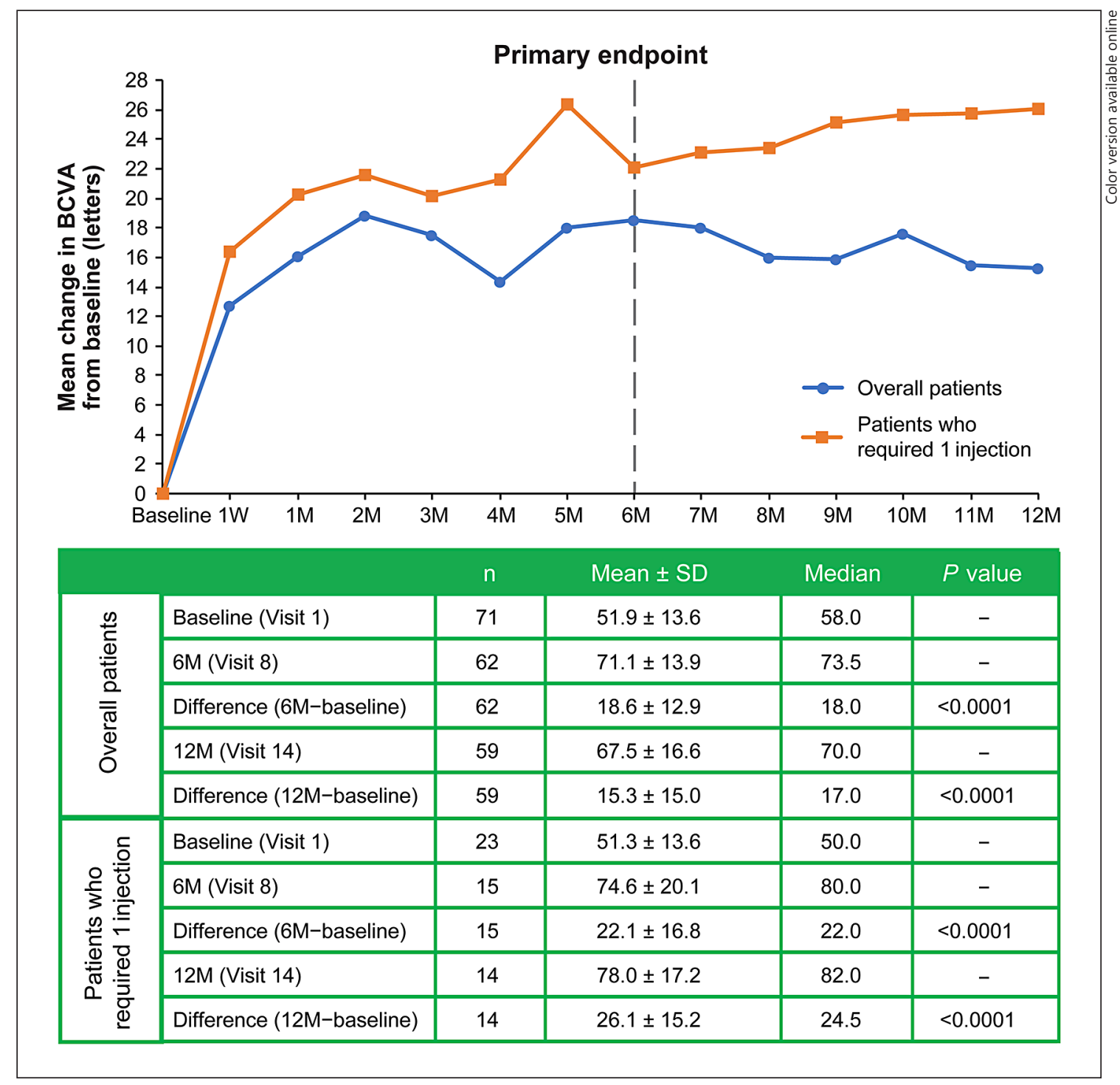

Fig. 1. Mean change in BCVA from baseline at each visit. BCVA, best-corrected visual acuity; $M$, month(s); W, week.

Rescue treatment with laser photocoagulation was allowed 3 months after implant injection in patients who experienced a decrease of $\geq 10$ letters in BCVA from baseline due to worsening BRVO-associated ME at two consecutive visits at least 4 weeks apart. At every study visit, patients were assessed for additional treatment. Retreatment with dexamethasone intravitreal implant was allowed if $>4$ months had passed since the last injection, CRT was $>290 \mu \mathrm{m}$, or BCVA was $<84$ letters ( $<20 / 20$ Snellen equivalent) with recurrent $\mathrm{ME}$, and visual acuity decrease was attributable to BRVO-associated ME and not to other ocular conditions (e.g., cataract, epiretinal membrane, vitreomacular traction). Rescue treatment with laser photocoagulation was allowed 3 months after the implant injection in patients who experienced a decrease of $\geq 10$ letters in BCVA from baseline due to worsening BRVO-associated $\mathrm{ME}$ at two consecutive visits at least 4 weeks apart.

Dexamethasone Implant for Macular Edema due to BRVO

\section{Assessments}

Eligible patients were screened (visit 0), and baseline assessments were performed at day 0 (visit 1 ). Follow-up visits took place on day 7 (visit 2) and at months 1-12 (visits 3-14). A safety followup was done 2-7 days after each injection. BCVA (Early Treatment Diabetic Retinopathy Study [ETDRS]), IOP, biomicroscopy, ophthalmoscopy, optical coherence tomography, and adverse events (AEs) were evaluated at each study visit, including baseline (day 0 ), day 7, and monthly follow-up visits for 12 months. Fluorescein angiography was assessed at screening, month 6 , and month 12 . Patients receiving retreatment were followed up monthly until a final visit at month 12 . All information was captured using electronic case report forms. 


\section{Endpoints}

The primary efficacy endpoint was mean change from baseline in BCVA at month 6. Secondary efficacy endpoints included the proportion of patients with an increase in BCVA of $\geq 15$ letters at months 6 and 12, the mean change in BCVA from baseline at month 12, the mean change in CRT from baseline at months 6 and 12 , and the extent of leak assessed using fluorescein angiography. The total area of nonperfusion within the ETDRS grid was calculated as the macular nonperfusion area. The safety endpoints were the proportion of AEs tabulated by nature, severity, and frequency and assessed as changes in vital signs, IOP, biomicroscopy, and ophthalmoscopy. AEs were classified as related or unrelated to the study drug.

\section{Statistical Analysis}

Assuming a mean change in BCVA from baseline of 5.0 [11] at month 6 and an SD of 10.6 [11], a sample size of 48 patients was needed, and assuming a dropout rate of $30 \%$, approximately 70 patients needed to be recruited. In the analyses, continuous variables were summarized as mean $\pm \mathrm{SD}$, and categorical variables were summarized as frequency and percentage.

The intention-to-treat population, consisting of all enrolled patients, was used for the efficacy analyses and the summary of data other than safety variables. The safety population, consisting of all enrolled and treated patients, was used for safety analyses.

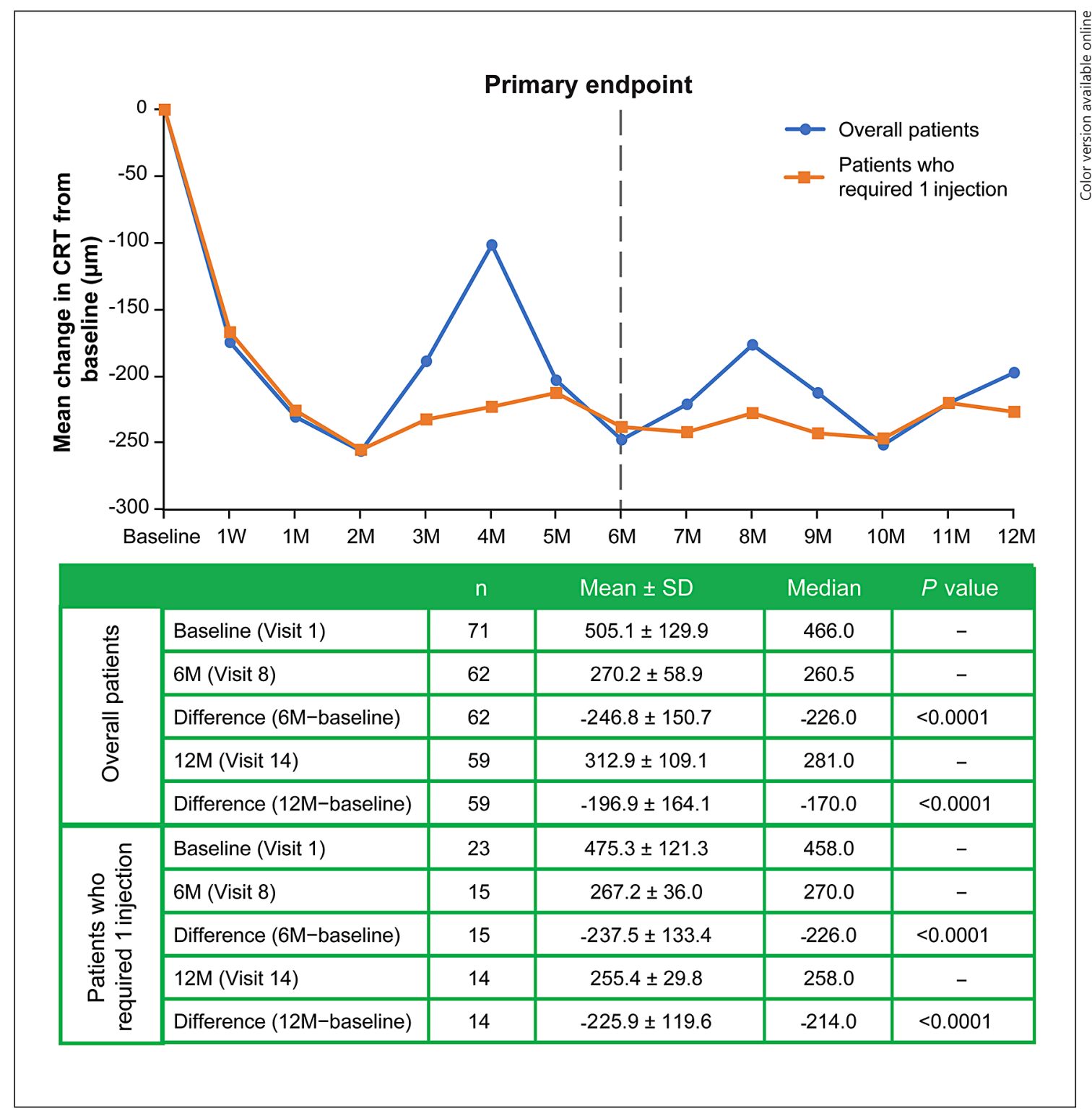

Fig. 2. Mean change in CRT from baseline at each visit. CRT, central retinal thickness; $M$, month(s); W, week. 


\section{Results}

Of the 71 patients enrolled, 59 completed the 12 -month study period. Six patients did not meet the study entry criteria (they dropped out after being injected), 1 met the entry criteria but did not receive the study drug, 2 were lost to follow-up, 2 withdrew consent, and 1 discontinued because of an AE. Therefore, the intention-to-treat and safety populations comprised 71 and 70 patients, respectively. Of these patients, 62 and 59 patients completed the study at months 6 and 12, respectively. The mean age was $57.5 \pm 9.2$ years, and $54 \%$ were men. The duration of ME at baseline visit was $<1$ month in $>70 \%$ of patients, with a median (range) duration of 16 (1-84) days. At baseline, intraretinal fluid was identified in all patients, and BCVA

Table 1. Proportion of patients gaining/losing different numbers of letters in BCVA (efficacy population)

\begin{tabular}{lcc}
\hline $\begin{array}{l}\text { Gain/loss of letters } \\
\text { in BCVA }\end{array}$ & $\begin{array}{l}\text { At 6 months } \\
(n=62)\end{array}$ & $\begin{array}{l}\text { At 12 months } \\
(n=59)\end{array}$ \\
\hline Gain & & \\
$\geq 15$ & $40(65 \%)$ & $33(56 \%)$ \\
$10-14$ & $12(19 \%)$ & $7(12 \%)$ \\
$5-9$ & $3(5 \%)$ & $8(14 \%)$ \\
$0-4$ & $5(8 \%)$ & $2(3 \%)$ \\
\hline Loss & & \\
$0-4$ & $0(0 \%)$ & $4(7 \%)$ \\
$5-9$ & $1(2 \%)$ & $0(0 \%)$ \\
$10-14$ & $0(0 \%)$ & $2(3 \%)$ \\
$\geq 15$ & $1(2 \%)$ & $3(5 \%)$ \\
\hline
\end{tabular}

Data are presented as $n(\%)$. BCVA, best-corrected visual acuity. and CRT were $51.9 \pm 13.6$ letters and $505.1 \pm 129.9 \mu \mathrm{m}$, respectively.

Approximately $70 \%$ of the maximum treatment response was seen as early as day 7 , with a mean \pm SD improvement in BCVA of $12.8 \pm 10.7$ letters $(n=70$; $p<$ 0.0001; paired $t$ test) (Fig. 1) and a decrease in CRT of $173.7 \pm 140.6 \mu \mathrm{m}(n=70 ; p<0.0001)$ (Fig. 2$)$. At the primary endpoint (month 6), patients had a significant improvement in BCVA from baseline $(n=62 ; 18.6 \pm 12.9$ letters; $p<0.0001$; 95\% CI 15.4-21.8) (Fig. 1) and a decrease in CRT from baseline $(n=62 ; 246.8 \pm 150.7 \mu \mathrm{m}$; $p<0.0001$ ) (Fig. 2). Similar changes from baseline were observed at month $12(n=59$; BCVA improvement of $15.3 \pm 15.0$ letters, $p<0.0001$; CRT decrease of $196.9 \pm$ $164.1 \mu \mathrm{m}, p<0.0001)$. At months 6 and 12, 65 and 56\% of patients had a gain of $\geq 15$ letters ( $\geq 3$ ETDRS lines), respectively (Table 1 ).

Over the 12 -month period, 32,18 , and $49 \%$ of patients received 1,2, and 3 dexamethasone intravitreal implant injections, respectively, with a mean \pm SD interval of 20.0 \pm 5.0 weeks. Twenty-nine $(41 \%)$ of the 71 patients received a second injection 4 months after the first one, of whom 2 did not require a third injection. Of the 35 patients who received a third injection, 20 were injected at baseline, 4 months, and 8 months; 5 at baseline, 4 months, and 9 months; 2 at baseline, 4 months, and 10 months; 4 at baseline, 5 months, and 9 months; 1 at baseline, 5 months, and 10 months; 2 at baseline, 5 months, and 11 months; and 1 at baseline, 6 months, and 10 months.

The mean CRT of the patients who required only 1 injection during the 12-month follow-up was significantly thinner compared to that of the patients who required 3 injections with 4 -month intervals: $506.5 \pm 108.7$ vs. 644.7 $\pm 171.2 \mu \mathrm{m}(p<0.016)$ (Table 2). Additionally, the patients who received only 1 injection had a significantly

Table 2. Baseline characteristics of patients who received 1 injection during the 12 -month follow-up (1Q12M) versus those who received 3 injections at 4-month intervals (3Q4M)

\begin{tabular}{lccc}
\hline & 1Q12M $(n=16)$ & 3Q4M $(n=20)$ & $p$ value \\
\hline Age, years & $53.3 \pm 7.9$ & $58.7 \pm 11.0$ & $0.049^{*}$ \\
Duration of symptoms, days & $20.0 \pm 16.8$ & $24.0 \pm 14.9$ & $0.249^{*}$ \\
Initial BCVA, ETDRS letters & $53.3 \pm 12.9$ & $48.6 \pm 13.6$ & $0.149^{*}$ \\
Initial CRT, $\mu \mathrm{m}$ & $506.5 \pm 108.7$ & $644.7 \pm 171.2$ & $0.016^{*}$ \\
Macular nonperfusion availability & $9 / 16$ & $14 / 20$ & $0.033^{*}$ \\
Macular nonperfusion, \% & $12.9 \pm 14.2$ & $26.7 \pm 11.7$ & \\
\hline
\end{tabular}

Data are presented as mean \pm SD or $n / N .{ }^{*}$ Mann-Whitney test. BCVA, best-corrected visual acuity; CRT, central retinal thickness; ETDRS, Early Treatment Diabetic Retinopathy Study. 
Fig. 3. Percentage of patients with an IOP change of $\geq 10 \mathrm{~mm} \mathrm{Hg}$ from baseline (a) and IOP of $\geq 25 \mathrm{~mm} \mathrm{Hg}$ (b). IOP, intraocular pressure; $\mathrm{M}$, month(s); W, week.

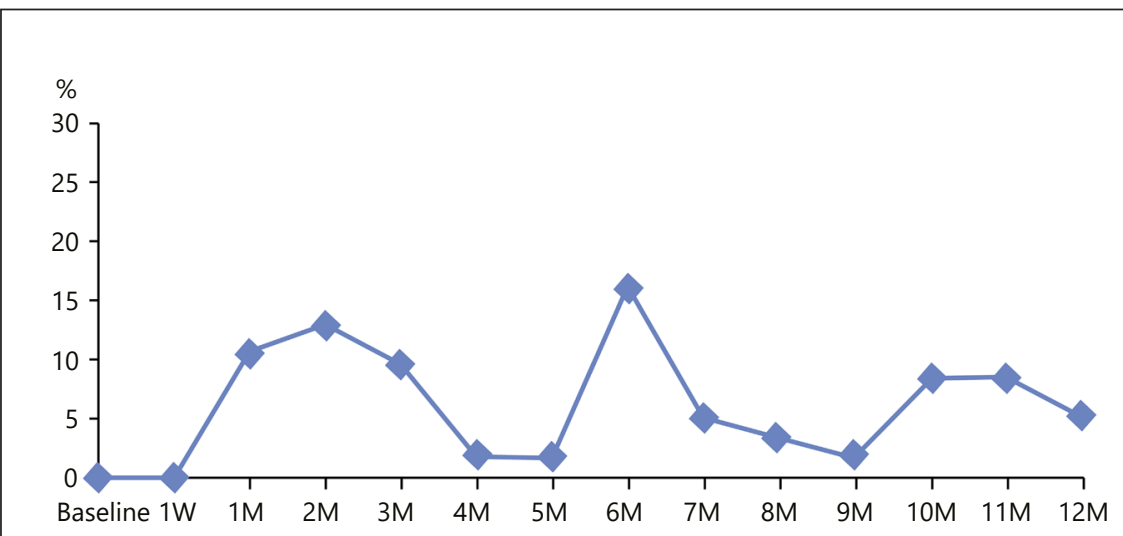

a

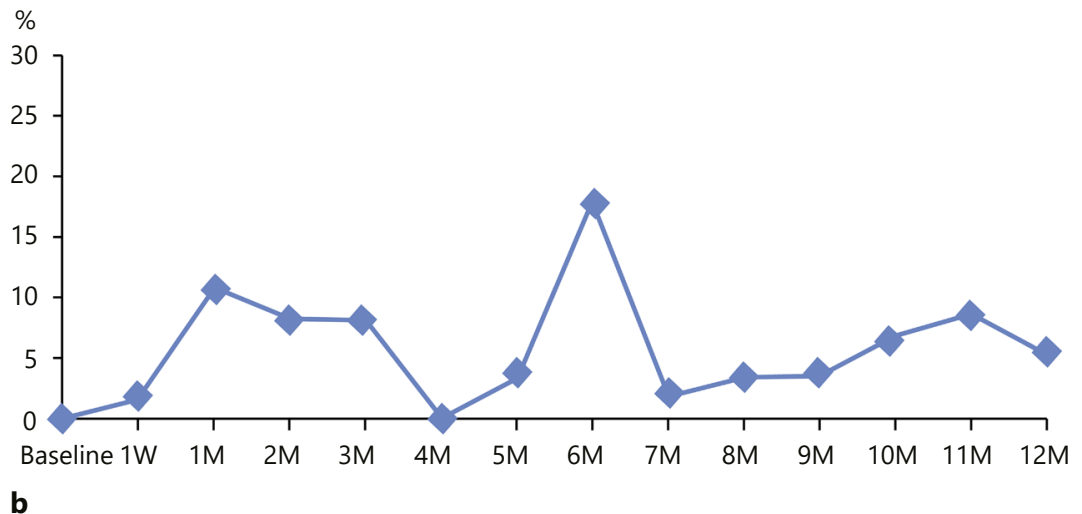

b

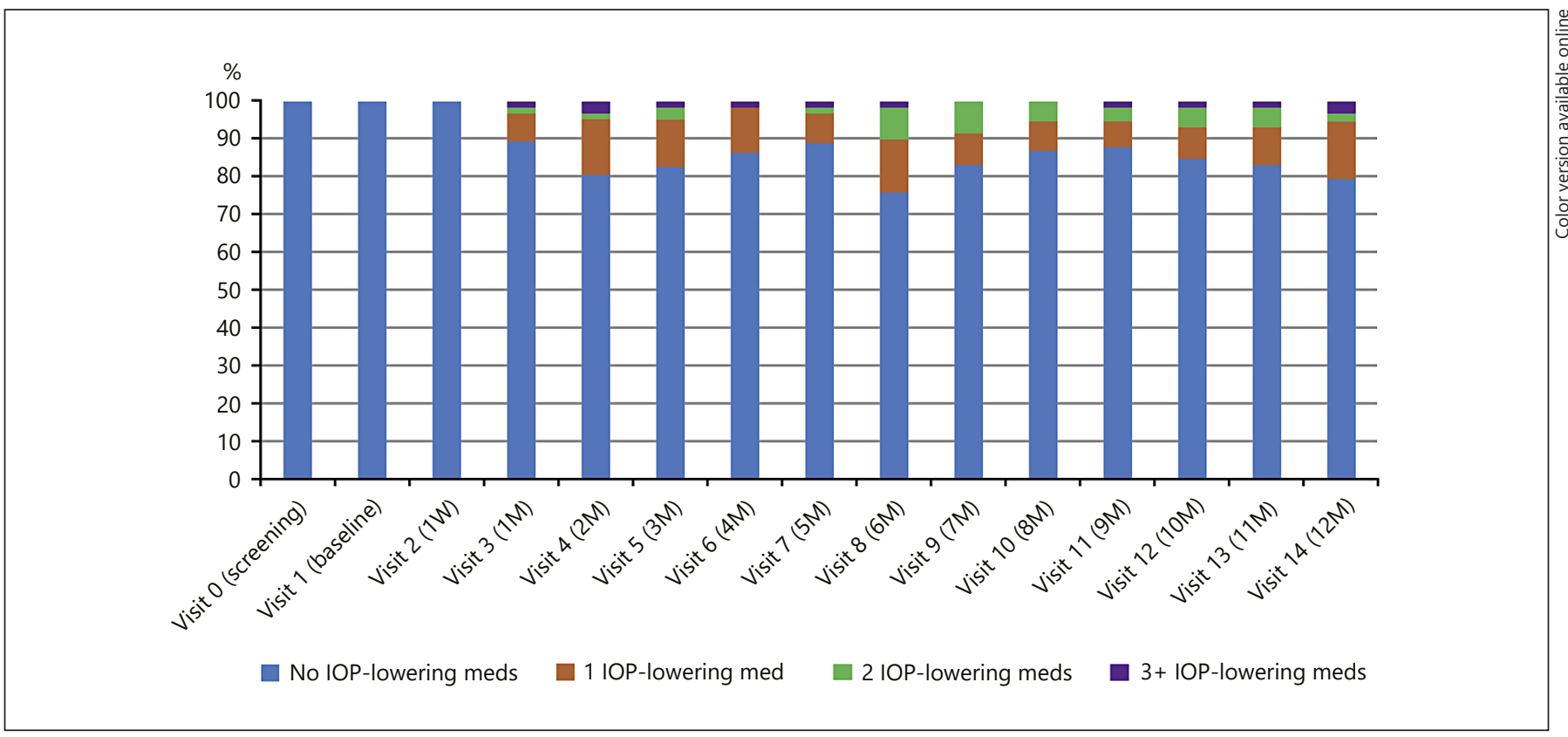

Fig. 4. Percentage of patients by number of topical IOP-lowering medications. IOP, intraocular pressure; M, month(s); med, medication; W, week. 
Table 3. Drug-related AEs (safety population, $n=71$ )

\begin{tabular}{lcl}
\hline AEs & $\begin{array}{l}\text { Patients with } \\
\text { AEs }\end{array}$ & $\begin{array}{l}\text { Number of } \\
\text { AEs }\end{array}$ \\
\hline Increased IOP & $25(35 \%)$ & 44 \\
Cataract & $11(16 \%)$ & 11 \\
Vitreous detachment & $4(6 \%)$ & 4 \\
Conjunctival hemorrhage & $3(4 \%)$ & 3 \\
Ptosis & $2(3 \%)$ & 3 \\
Chorioretinopathy & $1(1 \%)$ & 1 \\
Glaucoma & $1(1 \%)$ & 1 \\
\hline Total & $35(49 \%)$ & 67 \\
\hline
\end{tabular}

Data are presented as $n$ or $n(\%)$. AE, adverse event; IOP, intraocular pressure.

lower nonperfusion area $(12.9 \pm 14.2 \%)$ at baseline as compared to the patients who received 3 injections at intervals of 4 months $(26.7 \pm 11.7 \%)$. No patient required rescue treatment.

Overall, 52 patients experienced 131 AEs, 67 (51.2\%) of them being considered drug or procedure related (Table 3). One patient developed ovarian cancer (unrelated to treatment) and discontinued the study. The most common (>5\%) AEs were increased IOP (35\%), newly diagnosed cataract (16\%), and posterior vitreous detachment (6\%). An IOP of $\geq 25 \mathrm{~mm} \mathrm{Hg}$ was experienced by $18 \%$ of patients, but all were managed with IOP-lowering medications (Fig. 3, 4). At the last visit, 12 of 59 (20\%) patients were receiving IOP-lowering medications. In total, 19 of $53(36 \%)$ patients showed progression of lens opacity. One patient required cataract extraction.

\section{Discussion}

The results of this study demonstrate that early treatment of BRVO-associated ME with dexamethasone intravitreal implant can safely lead to significant improvement in BCVA and concomitant reduction in CRT over 6 and 12 months. Interestingly, the BCVA improvement of 18.6 ETDRS letters at 6 months observed in this study is similar to that in previous studies using monthly antiVEGF injections $[15,16]$. Importantly, treatment response occurred as early as at week 1 , when approximately $70 \%$ of the maximum improvement in BCVA and reduction in CRT was observed. This is a novel finding. Significant improvement with dexamethasone intravitreal $(0.7 \mathrm{mg})$ implant was observed as early as at the first

Dexamethasone Implant for Macular

Edema due to BRVO efficacy visit (day 30) and persisted through day 180 in the GENEVA study (improvement $\geq 15$ letters: 21 and $22 \%$, respectively) [11]. Of note, the first efficacy assessment was done on day 30 in the GENEVA study versus at week 1 in the present study. The results also are consistent with those from studies evaluating triamcinolone or bevacizumab therapy in patients with BRVO-associated ME [17]. Compared with other studies of dexamethasone intravitreal implants, our BCVA results were better, possibly related to multiple factors, including the duration of $\mathrm{ME}$ at baseline and retreatment intervals. The proportion of patients in this study who had symptoms of ME for $<90$ days was $100 \%$, as opposed to $16 \%$ in the GENEVA study. Additionally, retreatment was allowed as frequently as every 4 months in our study, as opposed to an interval of at least 6 months after the first injection in the GENEVA study. These factors may have contributed to better efficacy results observed in our study, which also reflects real-world practice patterns, unlike the GENEVA study.

At months 6 and 12, a gain of $\geq 15$ letters ( $\geq 3$ ETDRS lines) was seen in 65 and $56 \%$ of patients, respectively. In the present study, median (range) BRVO-associated ME duration was 16 (1-84) days at baseline. The results of recent studies showed that treatment of BRVO as early as 2 weeks after onset of ME enhanced visual outcome [14], while delayed treatment negatively impacted efficacy [11, $13,14]$. In a study of Korean patients, the proportion of BRVO patients with improvement in BCVA of $\geq 3$ lines at 6 months after treatment decreased $(64,53,39,38$, and $21 \%$; $p<0.019)$ as the duration of ME at baseline increased (<2 weeks, 2-4 weeks, 1-2 months, 2-3 months, and 3-6 months, respectively) [14]. Of note, $64 \%$ of patients with ME duration $\leq 2$ weeks had a line gain of $\geq 3$ in that study [14], which is similar to the $65 \%$ observed in the present study. In contrast, only $22 \%$ of the patients in the GENEVA study - where mean ME duration was 157.6 days - achieved a gain of $\geq 15$ letters on day 180 [11]. For comparison, only $16.4 \%$ of eyes had a ME duration $<90$ days in the GENEVA study versus all patients in the present study. Further, patients received only one dexamethasone implant in the GENEVA study [11] versus up to three implants in the present study. Early treatment with dexamethasone and retreatment at optimal intervals likely account for the difference in efficacy observed in the present study.

The efficacy of early treatment and retreatment as needed is further supported by the observation that the proportion of eyes with worsening of $\geq 15$ letters from baseline in the present study was $2 \%$ at month 6 and $5 \%$ 
at month 12. These rates are lower than those reported for the GENEVA study, where 6,7 , and $11 \%$ of patients in the $0.7 \mathrm{mg}$ dexamethasone, $0.35 \mathrm{mg}$ dexamethasone, and sham treatment groups, respectively, experienced a loss of $\geq 15$ letters from baseline on day 180 [11].

The response to treatment with dexamethasone intravitreal implant may last between 90 and 180 days, depending on the patient population and the outcome measure. About $32 \%$ of patients required a single implant injection, and - among those needing retreatment - the optimal retreatment interval was approximately 5 months. The results of this study suggest that the optimal retreatment interval is approximately 5 months in this patient population, although $41 \%$ of patients required a second dexamethasone intravitreal implant 4 months after the first one. In the present study, 35 of 71 patients required 3 injections during the 12-month follow-up. Among these patients, 20 were injected most frequently - at baseline, 4 months, and 8 months. Of note, patients who required 3 injections every 4 months showed a significantly thicker mean CRT and larger macular nonperfusion area compared to those who received only 1 injection over the whole study duration. Taken together, these results suggest that patients with BRVO whose CRT is $>600 \mu \mathrm{m}$ and who have significant macular nonperfusion should be reviewed more frequently, since these patients may require dexamethasone implants on a 4-monthly basis.

Approximately $67 \%$ of eyes required additional dexamethasone injections over the 12-month study period. In comparison, and likely accounting for differences in the efficacy results, a single dexamethasone implant was administered in the first 6 months of the GENEVA study [11]. The 5-month retreatment interval is similar to that observed in previous retrospective chart review studies $[18,19]$. In a retrospective chart review study of 289 patients (the SHASTA study), the median and mean time between two consecutive dexamethasone implants was 4.9 and 5.6 months, respectively [18]. In another chart review study of 33 eyes, between-treatment intervals were $4.7 \pm 1.1$ months after the first and $5.1 \pm 1.5$ months after the second dexamethasone intravitreal implant [19].

Notably, the AEs observed in this study were similar to those reported previously $[11,12,18-20]$. The most common (>5\%) AEs were increased IOP (35\%), cataract (16\%), and vitreous detachment (6\%). An IOP of $\geq 25$ $\mathrm{mm} \mathrm{Hg}$ was experienced by $18 \%$ of patients and was managed with IOP-lowering medications. One patient required cataract extraction, while 19 of 53 (36\%) patients showed progression of lens opacity. The incidence of increased IOP and cataract was much lower than that of steroid-induced ocular hypertension and progression of cataract reported with triamcinolone intravitreal injections $[21,22]$.

A potential limitation of the present study is the absence of a control group. Spontaneous improvement of visual acuity can occur in some patients with BRVO and early ME onset. The results of an evidence-based systematic review evaluating the natural history of BRVO showed that while $18-41 \%$ of patients with ME at baseline resolved spontaneously over a 1 -year period, clinically significant improvement beyond 20/40 was infrequent [23]. The improvement observed in the present study is beyond the range reported for spontaneous improvement. In today's treatment paradigm, when a patient presents with significant visual loss and macular thickening (consistent with the inclusion criteria of the present study), Korean physicians will start treatment, regardless of the duration of the symptoms; if treatment is delayed and the patient does not recover spontaneously, the outcome may be less effective than if treatment had been started initially. Nonetheless, further studies with sham or active controls (e.g., laser photocoagulation) are needed to completely understand the comparative efficacy and safety of the dexamethasone implant.

\section{Acknowledgments}

The authors express their sincere thanks to the patients, investigators, and research coordinators at each medical institution who participated in the COBALT study. This study was funded by Allergan Korea. The funding organization participated in the design of the study and interpretation of data as well as the preparation, review, and approval of the manuscript. Data management and statistical support was provided by Dream CIS, Inc., Seoul, Republic of Korea. Medical writing services were provided by Vidula Bhole, MD, MHSc, of Cactus Communications and funded by Allergan Korea. All authors had full access to all of the data in this study and take complete responsibility for the integrity of the data and accuracy of the data analysis.

\section{Statement of Ethics}

The study was performed in accordance with the principles of the Declaration of Helsinki and of good clinical practice. The study protocol was approved by the independent ethics committees of the respective investigational centers, including the institutional review boards of Asan Medical Center, Gangnam Severance Hospital, Kim's Eye Hospital, Kyungpook National University Hospital, Samsung Medical Center, Seoul National University Hospital, and Severance Hospital. Written informed consent was obtained from all participants at the screening visit.
Yoon/Kim/Lee/Kim/Kang/Yu/Koh/Kim/ Chang/Simonyi 


\section{Disclosure Statement}

Y.H. Yoon received a research grant from Allergan plc, consultant and speaker fees from Allergan plc during the conduction of this study, consultant and speaker fees from Alcon and Bayer outside of this study, and a research grant from Bayer outside of this study. J.Y. Lee received a research grant and other support from
Allergan during the conduction of this study as well as other support from Novartis outside of this study. H.G. Yu received a research grant from Allergan outside of this study. D.-J. Chang and S. Simonyi are full-time employees of Allergan Pte. Ltd., Singapore. J.W. Kim, I.T. Kim, S.W. Kang, H.J. Koh, and S.S. Kim have nothing to disclose.

\section{References}

1 Rehak J, Rehak M: Branch retinal vein occlusion: pathogenesis, visual prognosis, and treatment modalities. Curr Eye Res 2008;33 $111-131$.

$\checkmark 2$ Klein R, Klein BE, Moss SE, Meuer SM: The epidemiology of retinal vein occlusion: the Beaver Dam Eye Study. Trans Am Ophthalmol Soc 2000;98:133-141.

3 Mitchell P, Smith W, Chang A: Prevalence and associations of retinal vein occlusion in Australia. The Blue Mountains Eye Study. Arch Ophthalmol 1996;114:1243-1247.

4 Klein R, Moss SE, Meuer SM, Klein BE: The 15 -year cumulative incidence of retinal vein occlusion: the Beaver Dam Eye Study. Arch Ophthalmol 2008;126:513-518.

5 Finkelstein D: Argon laser photocoagulation for macular edema in branch vein occlusion. Ophthalmology 1986;93:975-977.

-6 Campochiaro PA, Hafiz G, Shah SM, Nguyen QD, Ying H, Do DV, Quinlan E, ZimmerGaller I, Haller JA, Solomon SD, Sung JU, Hadi Y, Janjua KA, Jawed N, Choy DF, Arron JR: Ranibizumab for macular edema due to retinal vein occlusions: implication of VEGF as a critical stimulator. Mol Ther 2008; 16 : 791-799.

7 Scott IU, Ip MS, VanVeldhuisen PC, Oden NL, Blodi BA, Fisher M, Chan CK, Gonzalez VH, Singerman LJ, Tolentino M; SCORE Study Research Group: A randomized trial comparing the efficacy and safety of intravitreal triamcinolone with standard care to treat vision loss associated with macular edema secondary to branch retinal vein occlusion: the Standard Care vs Corticosteroid for Retinal Vein Occlusion (SCORE) study report 6. Arch Ophthalmol 2009;127:1115-1128.

8 Jonas JB, Akkoyun I, Kamppeter B, Kreissig I, Degenring RF: Branch retinal vein occlusion treated by intravitreal triamcinolone acetonide. Eye (Lond) 2005;19:65-71.

-9 Garweg JG, Zandi S: Retinal vein occlusion and the use of a dexamethasone intravitreal implant $\left(\right.$ Ozurdex $\left.^{\circledR}\right)$ in its treatment. Graefes Arch Clin Exp Ophthalmol 2016;254:12571265.
10 Danis RP, Sadda S, Jiao J, Li XY, Whitcup SM: Relationship between retinal thickness and visual acuity in eyes with retinal vein occlusion treated with dexamethasone implant. Retina 2016;36:1170-1176.

-11 Haller JA, Bandello F, Belfort R Jr, Blumenkranz MS, Gillies M, Heier J, Loewenstein A, Yoon YH, Jacques ML, Jiao J, Li XY, Whitcup SM; OZURDEX GENEVA Study Group: Randomized, sham-controlled trial of dexamethasone intravitreal implant in patients with macular edema due to retinal vein occlusion. Ophthalmology 2010;117:1134-1146. e3.

12 Haller JA, Bandello F, Belfort R Jr, Blumenkranz MS, Gillies M, Heier J, Loewenstein A, Yoon YH, Jiao J, Li XY, Whitcup SM; OZURDEX GENEVA Study Group, Li J: Dexamethasone intravitreal implant in patients with macular edema related to branch or central retinal vein occlusion: twelve-month study results. Ophthalmology 2011;118:2453-2460.

13 Yeh WS, Haller JA, Lanzetta P, Kuppermann BD, Wong TY, Mitchell P, Whitcup SM, Kowalski JW: Effect of the duration of macular edema on clinical outcomes in retinal vein occlusion treated with dexamethasone intravitreal implant. Ophthalmology 2012;119: 1190-1198.

14 Yoon YH, Kim HK, Yoon HS, Kang SW, Kim JG, Park KH, Jo YJ, Lee JY, Lee DH; Korean RVO Study Group: Improved visual outcome with early treatment in macular edema secondary to retinal vein occlusions: 6-month results of a Korean RVO study. Jpn J Ophthalmol 2014;58:146-154.

15 Campochiaro PA, Heier JS, Feiner L, Gray S, Saroj N, Rundle AC, Murahashi WY, Rubio RG; BRAVO Investigators: Ranibizumab for macular edema following branch retinal vein occlusion: six-month primary end point results of a phase III study. Ophthalmology 2010;117:1102-1112.e1.
6 Campochiaro PA, Clark WL, Boyer DS, Heier JS, Brown DM, Vitti R, Kazmi H, Berliner AJ, Erickson K, Chu KW, Soo Y, Cheng Y, Haller JA: Intravitreal aflibercept for macular edema following branch retinal vein occlusion: the 24-week results of the VIBRANT study. Ophthalmology 2015;122:538-544.

17 Kim JY, Park SP: Comparison between intravitreal bevacizumab and triamcinolone for macular edema secondary to branch retinal vein occlusion. Korean J Ophthalmol 2009; 23:259-265.

18 Capone A Jr, Singer MA, Dodwell DG, Dreyer RF, Oh KT, Roth DB, Walt JG, Scott LC, Hollander DA: Efficacy and safety of two or more dexamethasone intravitreal implant injections for treatment of macular edema related to retinal vein occlusion (SHASTA study). Retina 2014;34:342-351.

19 Querques L, Querques G, Lattanzio R, Gigante SR, Del Turco C, Corradetti G, Cascavilla ML, Bandello F: Repeated intravitreal dexamethasone implant $\left(\right.$ Ozurdex $^{\circledR}$ ) for retinal vein occlusion. Ophthalmologica 2013;229: 21-25.

20 Allergan Inc.: Ozurdex ${ }^{\circledR}$ (dexamethasone intravitreal implant) $0.7 \mathrm{mg}$. 2016. http://cial. allergan.com/products/eye_care/ozurdex. htm (accessed July 11, 2016).

21 Cekic O, Chang S, Tseng JJ, Barile GR, Del Priore LV, Weissman H, Schiff WM, Ober $\mathrm{MD}$ : Intravitreal triamcinolone injection for treatment of macular edema secondary to branch retinal vein occlusion. Retina 2005;25: 851-855.

22 Chen SD, Sundaram V, Lochhead J, Patel CK: Intravitreal triamcinolone for the treatment of ischemic macular edema associated with branch retinal vein occlusion. Am J Ophthalmol 2006;141:876-883.

23 Rogers SL, McIntosh RL, Lim L, Mitchell P, Cheung N, Kowalski JW, Nguyen HP, Wang JJ, Wong TY: Natural history of branch retinal vein occlusion: an evidence-based systematic review. Ophthalmology 2010;117:1094-1101. 